\title{
A INCONSTITUCIONALIDADE DE HONORÁRIOS SUCUMBENCIAIS E A JUSTIÇA GRATUITA NO PROCESSO DE TRABALHO
}

\author{
THE UNCONSTITUTIONALITY OF SUCUMBENENCY FEES AND FREE \\ JUSTICE IN THE WORK PROCESS
}

\begin{abstract}
Rasquim Teixeira ${ }^{1}$
RESUMO: A justiça gratuita é um direito à pessoa com insuficiência de recursos para arcar com às custas judiciais, despesas processuais e honorários advocatícios. Outrora, sabe-se que os honorários sucumbenciais são valores que a Lei impõe aos advogados para que fixem em decorrência do seu trabalho prestado. Deste modo, quando o advogado ganha uma causa, o juiz pode decidir que a parte perdedora arque com as despesas advocatícias da parte vencedora, em benefício a esta. Nesse sentido, o objetivo deste artigo foi verificar quais os reflexos dos honorários sucumbenciais aos detentores da justiça gratuita nos processos de trabalho. Diante disso fez-se um levantamento bibliográfico e documental que contribuiu com o tema exposto, observando o entendimento trazido pela doutrina e de outros autores conceituados.
\end{abstract}

Palavras-chave: Justiça gratuita. Honorários ducumbenciais. Direito do trabalho.

ABSTRACT: Free justice is a right to the person with insufficient resources to pay at court costs, procedural expenses and attorney's fees. Once, it is known that the succumbing fees are amounts that the Law imposes on lawyers to fix as a result of their work. Thus, when the lawyer wins a case, the judge may decide that the losing party charges the winning party's legal costs to the benefit of it. In this sense, the aim of this article was to verify the reflexes of the succumbing fees to the holders of free justice in the work processes. Therefore, a bibliographic and documentary survey was made that contributed to the theme exposed, observing the understanding brought by the doctrine and other conceptual authors.

Keywords: Free Justice. Succumbing fees. Labour Law.

\footnotetext{
${ }^{1}$ Formado em direito universidade do sul de santa catarina-UNISUL. Pós-Graduado latu sensu Especialização em tendências contemporâneas do direito processual - Modalidade formação para o mercado de trabalho. Universidade do extremo sul catarinense. Professor de direito penal. Processo penal e direito constitucional- Aprovar curso preparatório para concursos. Professor de direito penal, processo penal e direito constitucional- Gabarito curso preparatório para concursos aprovar curso preparatório para concursos. Advogado geral- Igreja assembleia de Deus da cidade de içara - Santa catarina. advogado dativo- Poder judiciário do estado de santa catarina. Email: rasquim.teixeirazon@gmail.com
} 


\section{INTRODUÇÃO}

Diante da importância em tornar efetivo o princípio da igualdade, o Estado Democrático de Direito entendeu que a justiça anda em consonância com o bem social desde que todos sejam tratados igualmente à medida de sua desigualdade. Assim, garantiu-se aos mais necessitados o direito à justiça gratuita para que pudessem ter oportunidade de se igualar aos demais em suas necessidades, ainda mais quando necessário atendimento judicial.

Em 2017 ocorreu a Reforma Trabalhista, dada pela Lei $\mathrm{n}^{\circ}$ 13.467/17, todavia, anterior a ela, como uma peculiaridade via-se que não existia incidência de honorários sucumbenciais nos processos trabalhistas, interpretações obtidas pelas súmulas 219 e 329 do TST. O entendimento concedido permitia que partes hipossuficientes não se intimidassem perante aos direitos buscados contra a parte empregadora.

Contudo, em meio ao entendimento supracitado, observou-se que com a Reforma Trabalhista àquele já não se impunha, uma vez que agora seria possível incidir honorários de sucumbência mesmo que a parte que vença seja beneficiária da

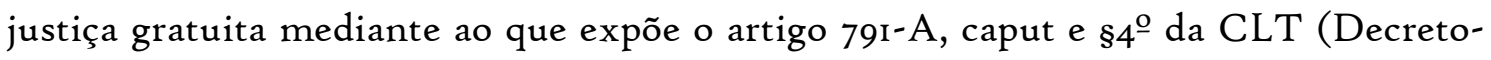
lei $\mathrm{n}^{-}$5.452, de $\mathrm{I}^{\mathrm{a}}$ de maio de $\left.\mathrm{r} .943\right)^{2}$.

Em meio ao exposto não se pode negar o fato de que aplicar a sucumbência em desfavor do empregado, que por maioria das vezes, é a parte hipossuficiente, fere a constitucionalidade concedida pela justiça gratuita. Não se observa a permissão concedida em direito de todos no processo de trabalho, deste modo.

Art. 79I-A. Ao advogado, ainda que atue em causa própria, serão devidos honorários de sucumbência, fixados entre o mínimo de $5 \%$ (cinco por cento) e o máximo de $15 \%$ (quinze por cento) sobre o valor que resultar da liquidação da sentença, do proveito econômico obtido ou, não sendo possível mensurálo, sobre o valor atualizado da causa $[. .].[\ldots] \S 4^{\circ}$. Vencido o beneficiário da justiça gratuita, desde que não tenha obtido em juízo, ainda que em outro processo, créditos capazes de suportar a despesa, as obrigações decorrentes de sua sucumbência ficarão sob condição suspensiva de exigibilidade e somente poderão ser executadas se, nos dois anos subsequentes ao trânsito em julgado da decisão que as certificou, o credor demonstrar que deixou de existir a situação de insuficiência de recursos que justificou a concessão de gratuidade, extinguindo-se, passado esse prazo, tais obrigações do beneficiário. (BRASIL, 2018). 


\section{A JUSTIÇA GRATUITA NO ÂMBITO TRABALHISTA E OS HONORÁRIOS DE SUCUMBÊNCIA}

A criação da justiça gratuita teve seu pilar estabelecido pela Constituição Federal de 1988, em seu artigo $5^{\circ}$, inciso LXXIV, que retrata: "o Estado prestará assistência jurídica integral e gratuita aos que comprovarem insuficiência de recursos" (BRASIL, I988). Inserido no rol de direitos e garantias individuais é mister ressaltar que foi um retrocesso constitucional quando da ocorrência da Reforma Trabalhista de 2017 .

A Consolidação das Leis do Trabalho (CLT), também manifesta gratuidade da justiça em seu artigo 790 §§ $3^{\circ}$ e $4^{\underline{0}^{3}}$, corroborando o que retrata a Carta Maior. O Código de Processo Civil reforça tal concessão em seu artigo 98, que traz: “a pessoa natural ou jurídica, brasileira ou estrangeira, com insuficiência de recursos para pagar as custas, as despesas processuais e os honorários advocatícios tem direito à gratuidade da justiça, na forma da lei”. Ainda, seu § $I^{\circ}$ menciona o direito à isenção de taxas judiciárias, custas, emolumentos e despesas com editais. Importa dizer que quando aplicado ao direito trabalhista cabe cobrança de honorários periciais, quando do vencimento da parte (BRASIL, 2015).

A Constituição Federal traz em seu artigo 133 o seguinte: “o advogado é indispensável à administração da justiça, sendo inviolável por seus atos e manifestações no exercício da profissão, nos limites da lei” (BRASIL, 1988). Assim, traça-se figura do advogado como peça essencial ao processo judicial, possuindo grande significado para que a justiça seja efetivada.

Corrobora entendimento Nascimento (2002, p.348) que o advogado é “indispensável à administração da justiça, princípio cuja amplitude pode levar à exigibilidade da sua participação em todos os processos judiciais, independentemente da natureza e expressão econômica das causas".

\footnotetext{
${ }^{3} \S 3^{\circ}$ É facultado aos juízes, órgãos julgadores e presidentes dos tribunais do trabalho de qualquer instância conceder, a requerimento ou de ofício, o benefício da justiça gratuita, inclusive quanto a traslados e instrumentos, àqueles que perceberem salário igual ou inferior a $40 \%$ (quarenta por cento) do limite máximo dos benefícios do Regime Geral de Previdência Social.

$\S 4^{\circ} \mathrm{O}$ benefício da justiça gratuita será concedido à parte que comprovar insuficiência de recursos para o pagamento das custas do processo (BRASIL, 2017).
} 
Por conseguinte, mencionando acerca do valor direcionado ao advogado pelo serviço prestado, menciona Neves (2018, p. 279) que "os honorários advocatícios constituem a remuneração devida aos advogados em razão de prestação de serviços jurídicos, tanto em atividade consultiva como processual”. Logo, seria de justificativa plausível que seus serviços fossem pagos, mediante àquilo que lhes forneceu enquanto durou o processo.

As remunerações pelos serviços advocatícios se dão por duas formas, a primeira é em razão de honorários contratuais, gerado pelo cliente e o advogado e o acordo firmado. A segunda forma pé em decorrência dos honorários sucumbenciais, devido em vezes, pela vitória de seu cliente em um trâmite judicial (NEVES, 2018).

Diante dos ensinamentos de Cahali (1997), é válido ressaltar que os honorários sucumbenciais não foram de imediato aplicados no Brasil, mas somente a partir de 1939 pelo Código de Processo Civil vigente à época, quando em seus artigos 63 e 64 estabelecia tal intento como uma penalidade.

Em 2015 com o novo COC, o princípio da sucumbência foi consagrado consagrando-o em seu artigo 85 com a seguinte redação "a sentença condenará o vencido a pagar honorários ao advogado do vencedor" (BRASIL, 2015). Para fixação do valor, atenta-se ao parágrafo $2^{\circ}$ que traz: "os honorários serão fixados entre o mínimo de dez e o máximo de vinte por cento sobre o valor da condenação, do proveito econômico obtido ou, não sendo possível mensurá-lo, sobre o valor atualizado da causa" (BRASIL, 2015).

A disposição supra se rege pelo artigo 86 , descrevendo que "se cada litigante, em parte, for vencedor e vencido, serão proporcionalmente distribuídas entre eles as despesas" (BRASIL, 2015).

Em se tratando das leis de trabalho, antes da Reforma Trabalhista os honorários advocatícios sucumbenciais não tinham sido mencionados, uma vez que sua aplicabilidade se fazia apenas com as relações do CPC. Com a Lei n ${ }^{\circ} 13.467 / 2017$, adicionou-se o artigo 791-A, versando acerca dessa aplicabilidade agora nas relações de trabalho. 
Com a nova regulamentação dada pela Reforma Trabalhista, verifica-se em seu artigo 791-A, a inserção da possibilidade de fixar honorários sucumbenciais, conforme se vê:

\begin{abstract}
Art. 791-A. Ao advogado, ainda que atue em causa própria, serão devidos honorários de sucumbência, fixados entre o mínimo de 5\% (cinco por cento) e o máximo de $15 \%$ (quinze por cento) sobre o valor que resultar da liquidação da sentença, do proveito econômico obtido ou, não sendo possível mensurá-lo, sobre o valor atualizado da causa (BRASIL, 2017).
\end{abstract}

Explica Rocha (2018) que diante da nova complexidade do processo trabalhista, há necessidade de um advogado em tal participação, não sendo possível validar contraditório e ampla defesa sem essa figura essencial, ou seja, é imposto tal ato apenas com profissional qualificado.

Ao analisar o artigo acima citado, verifica-se a garantia que o advogado possuirá em receber seus honorários sucumbenciais recíprocos sobre "o valor que resultar da liquidação da sentença, do proveito econômico obtido ou, não sendo possível mensurá-lo, sobre o valor atualizado da causa” (BRASIL, 2017).

Diante do contexto, importa salientar o entendimento trazido pela doutrina de Rocha (2018, p. I84) acerca da aplicabilidade do dispositivo em comento às causas trabalhistas:

\begin{abstract}
Assim, como na legislação processual civil e prestigiando o princípio da isonomia no que tange à atuação do advogado em qualquer ramo do Poder Judiciário, a Lei n. 13.467/2017 estabeleceu serem devidos os honorários de sucumbência, entre $5 \%$ e $15 \%$ sobre o valor de liquidação da sentença, sobre o proveito econômico obtido ou sobre o valor atualizado da causa, excluindo o entendimento jurisprudencial consubstanciado nas Súmulas n. 2197 e 329 do C. TST, que deverá ser revisado ou cancelado.
\end{abstract}

$\mathrm{Na}$ ótica do doutrinador restará valor devido à título de honorários sucumbenciais quando o litígio chegar ao fim. Se não ocorrer sua procedência ou se o processo for extinto sem decisão de mérito da causa, logo, o valor estipulado inicialmente à causa, será utilizado como valor dos honorários de sucumbência (ROCHA, 2018).

Entretanto, reforça Rocha (2018, p. 195) que o juiz deverá observar alguns requisitos para ser fixado o honorário, sendo: “a) o grau de zelo do profissional; b) o lugar da prestação do serviço; c) a natureza e a importância da causa; e d) o trabalho realizado pelo advogado e o tempo exigido para o seu serviço”. 
Todavia, ressaltam Gonçalves e colaboradores (2018) que em se tratando de gerar honorários de sucumbência às partes, seria notável observar que as mesmas disfrutam da mesma paridade socioeconômica, ao qual firmaram compromisso anterior de forma espontânea. Tal caso não ocorre em processos de trabalho, uma vez que nesse momento existe um elevado grau de disparidade, observando ainda, o dever de obediência marcado pela subordinação do empregado frente a seu empregador.

Em sequência, ao verificar o parágrafo $4^{\circ}$ do artigo 971-A da CLT, pode-se observar que até mesmo o beneficiário da justiça gratuita caberá pagamento desses honorários, conforme:

$\S 4^{\circ}$ Vencido o beneficiário da justiça gratuita, desde que não tenha obtido em juízo, ainda que em outro processo, créditos capazes de suportar a despesa, as obrigações decorrentes de sua sucumbência ficarão sob condição suspensiva de exigibilidade e somente poderão ser executadas se, nos dois anos subsequentes ao trânsito em julgado da decisão que as certificou, o credor demonstrar que deixou de existir a situação de insuficiência de recursos que justificou a concessão de gratuidade, extinguindo-se, passado esse prazo, tais obrigações do beneficiário (BRASIL, 2017).

Com a chegada da Lei $\mathrm{n}^{\circ} 13.467 / 2017$, os processos de trabalho passaram a ter resultados de incidência dos honorários de sucumbência nas lides trabalhistas às partes vencidas. Logo o Tribunal Superior do Trabalho trouxe entendimentos sumulados, trazidos pela Súmula 219 e 329 aos quais a aplicabilidade dos honorários de sucumbência era tidos como incorretos nos processos trabalhistas ${ }^{4}$ (BRASIL, 2017).

\footnotetext{
${ }^{4}$ SÚMULA 219: HONORÁRIOS ADVOCATÍCIOS. CABIMENTO (alterada a redação do item I e acrescidos os itens IV a VI em decorrência do CPC de 2015) - Res. 204/2016, DEJT divulgado em I7, I8 e 21.03.20I6 I - Na Justiça do Trabalho, a condenação ao pagamento de honorários advocatícios não decorre pura e simplesmente da sucumbência, devendo a parte, concomitantemente: a) estar assistida por sindicato da categoria profissional; b) comprovar a percepção de salário inferior ao dobro do salário mínimo ou encontrar-se em situação econômica que não lhe permita demandar sem prejuízo do próprio sustento ou da respectiva família. (art.14, $\S^{\circ}{ }^{\circ}$, da Lei $\mathrm{n}^{\mathrm{o}} 5.584 / 1970$ ). (ex-OJ no 305 da SBDII). II - É cabível a condenação ao pagamento de honorários advocatícios em ação rescisória no processo trabalhista. III - São devidos os honorários advocatícios nas causas em que o ente sindical figure como substituto processual e nas lides que não derivem da relação de emprego. IV - $\mathrm{Na}$ ação rescisória e nas lides que não derivem de relação de emprego, a responsabilidade pelo pagamento dos honorários advocatícios da sucumbência submete-se à disciplina do Código de Processo Civil (arts. 85, 86, 87 e 9o). V - Em caso de assistência judiciária sindical ou de substituição processual sindical, excetuados os processos em que a Fazenda Pública for parte, os honorários advocatícios são devidos
} 
Tal entendimento trazido em decorrência das súmulas citadas, se fez mediante ao fato de que antes da nova legislação, mesmo que o trabalhador fosse vencido no processo, o mesmo não iria arcar com custos tão onerosos. Nesse viés, ressalta-se que o artigo 79I-A passou a refletir nas custas judiciais mesmo que a parte vencida estivesse sendo beneficiada com a justiça gratuita (BRASIL, 20I7).

Assevera Costa (2019) que a Justiça do Trabalho dificulta o caráter probatório para o trabalhador frente ao seu empregador, por vezes, é comum que o reclamante não consiga documentar os fatos, contando apenas com a oitiva de testemunhas, um dos meios mais frágeis para serem considerados prova. Outrossim, quando inseridos os honorários sucumbenciais a essa realidade o acesso à justiça por este trabalhador hipossuficiente resta prejudicando. Por ocorrências como esta, o trabalhador acaba optando por continuar prejudicando ante ter que enfrentar processos judiciais gratuitos que podem se tornar onerosos.

Em meio a repercussão do fato, argui-se dizer que o Supremo Tribunal Federal entendeu ser inconstitucional os dispositivos advindos com a Reforma Trabalhista que fixam o pagamento de honorários periciais e sucumbenciais pela parte derrotada, mesmo que ela seja beneficiária da justiça gratuita. Contudo, o colegiado manteve válido o entendimento de que o pagamento das custas pelo beneficiário é cabível quando por ausência injustificada à audiência inicial (STF, 2021).

A Ação Direta de Inconstitucionalidade (ADIn) 5.766 foi ajuizada pela Procuradoria Geral da República (PGR), questionando a constitucionalidade dos artigos 790-B, caput e $\S 4^{\circ}$, 791-A, $\S 4^{\mathrm{o}}$, e art. 844, $\S^{2} 2^{\circ}$, todos da CLT. Em especial, foi alegado na ADIn que esses artigos violaram o devido processo legal e a garantia de acesso à Justiça do Trabalho por necessitados com direito à gratuidade de justiça (art. $5^{\circ}$, incisos XXXV, LIV e LXXIV, da Constituição).

entre o mínimo de dez e o máximo de vinte por cento sobre o valor da condenação, do proveito econômico obtido ou, não sendo possível mensurá-lo, sobre o valor atualizado da causa (CPC de 2015, art. $\left.85, \S 2^{\circ}\right)$. VI - Nas causas em que a Fazenda Pública for parte, aplicar-se-ão os percentuais específicos de honorários advocatícios contemplados no Código de Processo Civil.

SÚMULA 329: HONORÁRIOS ADVOCATÍCIOS. ART. 133 DA CF/1988 (mantida) - Res. I21/2003, DJ 19, 20 e 21.11.2003 Mesmo após a promulgação da CF/1988, permanece válido o entendimento consubstanciado na Súmula no 219 do Tribunal Superior do Trabalho. 
A ADIn argumentou diretamente pela seguinte causa:

Com propósito desregulamentar e declarado objetivo de reduzir o número de demandas perante a Justiça do Trabalho, a legislação avançou sobre garantias processuais e viola direito fundamental dos trabalhadores pobres à gratuidade judiciária, como pressuposto de acesso à jurisdição trabalhista. Assim o fez ao alterar os arts. 790-B caput e \$4 e e 791-A \$4º, da Consolidação, e autorizar o uso de créditos trabalhistas auferidos em qualquer processo, pelo demandante beneficiário da justiça gratuita, para pagar honorários periciais e advocatícios de sucumbência (ADI 57662017, p. $5-6)$.

É fato que muitos juristas vão de encontro com o alegado pela ADIn, quando consideram que a Reforma Trabalhista vai contra os direitos e garantias do trabalhador ainda mais no que se refere ao direito à justiça gratuita. Entretanto, o TST não leva adiante o entendimento ressaltado por doutrinadores e juristas, continuando a declarar constitucional a aplicação dos honorários de sucumbência mesmo aos que se beneficiam da justiça gratuita (PRITSCH et al., 20I9).

Em contribuição ao assunto, traz Schiavi (2017) que o legislador, ao possibilitar a previsão de sucumbência recíproca, acabou por configurar a alteração que mais possui significado na legislação, pois altera o protecionismo processual, pilar de sustentação do processo trabalhista. Deste modo, tal caso acaba sendo um fator que inibi o acesso à justiça para àquela parte economicamente mais fraca, ou seja, o trabalhador em face ao empregador.

Para Robles (2019), a mudança trazida com a Reforma Trabalhista acaba ensejando um contraponto, se por um lado, o pagamento de honorários de sucumbência, afeta o trabalhador que é a parte hipossuficiente, por outro lado, o não pagamento afeta a classe de advogados, pois ambos precisam receber para obter verba ao sustento e alimentação.

Diante dessa nova realidade, cabe agora ao judiciário se encarregar dos cuidados para que nenhum direito seja restringido, direitos estes, adquiridos ao longo da história da justiça trabalhista em que teve por base o acesso do trabalhador à justiça. Miziara (2017, p.1212) afirma que a "reforma acaba por impor a maior restrição à gratuidade de judiciária na Justiça do Trabalho quando em comparação com a Justiça Comum”. 
Para Robles (2019) mudanças como estas são estímulos à conscientização por parte da classe trabalhadora em reduzir o número de ações propostas na justiça contra seu empregador. Contudo, também enrijece a continuidade de luta pelos direitos trabalhistas, não podendo deixar de mencionar que muitos empregadores se aproveitam da desinformação de seus empregados para obter vantagens, fato que leva a uma disputa judicial.

\section{CONSIDERAÇÕES FINAIS}

Os honorários advocatícios sucumbenciais acabaram sendo uma mudança significativa na legislação trabalhista, ainda mais no que tange à possibilidade de o trabalhador ser beneficiário da justiça gratuita. Importa ressaltar que antes da imposição do artigo 791-A da CLT, não se ouvia falar nesta aplicabilidade em processos trabalhistas, o que acaba sendo satisfatório para o empregado, uma vez que não se via onerada sua causa, caso fosse perdida.

A partir do estímulo dado pelo legislador, o artigo 79I-A, adicionado à CLT com a Reforma Trabalhista significou a inutilização dos entendimentos contidos nas Súmulas 219 e 329 do TST. Isso fez com que o aceso à justiça gratuita fosse uma barreira para os trabalhadores hipossuficientes, aos quais agora, passariam a temer pela onerosidade de suas ações, visto que já não possuíam recursos econômicos suficientes para esta.

Mesmo visto a inconstitucionalidade marcada pelo fato, fato que viola o acesso livre ao judiciário, continua-se favorável a penalidade pelos honorários de sucumbência para a parte perdedora. Assim, diante de tanta luta no cenário trabalhista, acaba sendo visto um grande retrocesso a essa classe, vendo os princípios constitucionais sendo ultrajados. Também não se pode negar o imenso ataque à igualdade quando aplicado o artigo 791-A, fato que leva apenas os indivíduos com maior poder socioeconômico a ser capaz de lutar por seus direitos.

\section{REFERÊNCIAS}

BRASIL. Código de processo civil. 2015. Disponível em: http://www.planalto.gov.br/ccivil_ato2015-2018/2015/lei/li3105.htm. Acesso: 15 dez. 2021. 
BRASIL. Constituição federal de 1988. Disponível em: http://www.planalto.gov.br/ constituicao/constituicao.htm. Acesso: is dez. 2021.

BRASIL. Lei $\mathrm{n}^{\circ} \mathbf{1 3 . 4 6 7}$ de 13 de julho de 2017. Disponível em: http://www.planalto.gov.br /o2015-2018/2017/Lei/Li3467.htm\#artI. Acesso: 15 dez. 2021.

CAHALI, Yussef Said. Honorários advocatícios. 3. Ed. São Paulo: Revista dos Tribunais, 1997.

COSTA, Jorge Luiz. A reforma trabalhista e o pagamento de honorários sucumbenciais. Disponível em https://www.conjur.com.br/2or8-mai-o2/jorge-luiz-costareformatrabalhista-honorarios-sucumbenciais $>$ Acesso em: I9 dez. 202I.

GONÇALVES, Matheus Marinho. SILVA, Eloísa Rocha da. OLIVEIRA, Gabrielle Santos de. CAMPOS, Waleska Yone Yamakawa Zavatti. BRUM, André Luiz de Oliveira. Honorários sucumbenciais: a nova inclinação na Justiça do Trabalho. Disponível em: https://www.lex.com.br/doutrinainclinacao_na_justica_do_trabalho. Acesso: 19 dez. 202I.

NASCIMENTO, Amauri Mascaro. Curso de direito processual do trabalho. 2i. ed. São Paulo: Saraiva 2002.

PRITSCH. Cesar Zucatti, JUNQUEIRA. Fernanda Antunes Marques, MARANHÃO.Ney. Efeitos das primeiras decisões do TST sobre os honorários de sucumbência recíproca. Disponível em: https://www.conjur.com.br/2019-jul22/opiniaoprimeiras-decisoes-tst-sucumbencia-reciproca. Acesso: 19 dez. 202I.

MIZIARA, Raphael. Novidades em torno do benefício da justiça gratuita na CLT reformada e o ônus financeiro do processo. Revista LTr. Vol.8I, n⿳ำ 10 , p.1209- I216, 2017.

ROBLES, Natália Biondi Gaggini. Acesso à justiça na reforma trabalhista. São Paulo: Revista LTr, 2019.

ROCHA, Fábio Ribeiro da. Lei 13.467/2017 e os aspectos controvertidos do benefício constitucional da gratuidade judicial. Revista do Tribunal Regional do Trabalho. $3^{\underline{a}}$ Região, Belo Horizonte, v. 64, n. 97, p. 185-199, jan./jun. 2018.

STF derruba honorários de sucumbência em caso de justiça gratuita. Migalhas. 202I. Disponível em: https://www.migalhas.com.br/quentes/353470/stf-derruba-honorarios-desucumbencia-em-caso-de-justica-gratuita. Acesso: I6 dez. 2021.

SCHIAVI, Mauro. Reforma trabalhista e o processo do trabalho. São Paulo: Ltr, 2017.

NEVES, Daniel Amorim Assumpção. Manual de direito processual civil. ıo ed. São Paulo: Jus Podivm, 2018. 